\title{
Effect of procedures for clarifying the criterion setting on listening accuracy in the interview
}

\author{
ALLEN J. SCHUH \\ California State University, Hayward, California 94542
}

\begin{abstract}
Listening accuracy test scores were found to be $16 \%$ higher than a base rate established in previous research $(p<.001)$ when participants $(\mathrm{N}=36)$ were alerted that their listening would be tested and they were given a realistic expectation of what demands would be made on their memory upon completion of viewing a videotaped interview. Listening accuracy test scores were found to correlate significantly $(\mathrm{r}=.54, \mathrm{p}<.01)$ with the sum of three examination scores, thus replicating an earlier finding. It was concluded that procedures that clarify the criterion demands that will be made on memory increase the level of accuracy that interviewers achieve, but do not change the magnitude of the relationship between accuracy test scores and measures of accomplishment in training. Managers should assign to interviewing duties those personnel trainees who score highest on tests of related technical material.
\end{abstract}

Previous research (Schuh, 1978b) has shown listening accuracy in a simulated employment interview setting to be predictable from knowledge of trainees' examination scores in a course in personnel evaluation. In the previous research, the participants had been given a surprise test of listening accuracy. Cronbach (Note 1) suggested an extension of the original study because the purpose of listening seems to be an important factor. It was suggested that the results might have been different had the participants been shown what kind of test they were to be given after they had done their listening. The purpose of the present research was to test the effect of this variation in procedure.

\section{METHOD}

\section{Participants}

Participants $(\mathrm{N}=36)$ were students enrolled in a course in personnel evaluation. The course was required of undergraduates in the personnel/industrial relations major and consisted of lectures, discussions, and work samples.

\section{Apparatus}

The apparatus consisted of a Sony tape deck with a 21-in. Setchel-Carlson monitor. The audio-video tapes used in this study were three employment interviews of applicants dressed casually and seated across from an off-camera interviewer.

\section{Procedure}

There were three examinations during the quarter that followed the general outline of the required text (Cronbach, 1970). Examinations were composed of recognition and recall items. The sum of the three test scores was the predictor. The Kuder-Richardson Formula 21 reliability estimate for the total score was .83 .

During the last week of instruction, participants were shown the audio-video taped interviews in their classroom setting. The

Requests for reprints should be sent to Allen J. Schuh, School of Business and Economics, California State University, Hayward, California 94542. exercise was like many others during the quarter that were designed to give students a realistic view of what practicing personnel people typically do. The last part of the course would be the reasonable time to show such interviews because it corresponds to the section in Cronbach's (1970) text on typical measures of performance.

The apparatus was positioned in the classroom. After general introductory remarks by the professor, the equipment was operated and the interviews were seen by the students. During the introductory remarks, the participants were told that their listening ability (or verbal listening skill) would be tested with a 25-item multiple-choice test based on the transcript of the third interview they were about to see and hear. Participants were told that two preliminary interviews would be shown to give them a realistic expectation of the task that would be required of them.

The two preliminary interviews were shown. The first tape was a 10-min segment of an employment interview with a 22-year-old female accounting student who was seeking a position in hotel-restaurant management. The second tape was a 10-min segment of an employment interview with a 27-year-old male who was seeking a luxury automobile sales position. After each interview was shown, it was discussed and participants were alerted to the type of question that could have been expected had they been tested on the just-shown taped interview. The third interview was a $12-\mathrm{min}$ tape of a 26-year-old male who was completing the requirements of a MBA and was applying for a general management position.

Prior to showing the third interview, the experimenter reminded participants that they would be tested on their memory of what they were about to hear. After viewing the 12-min interview, the students were instructed to put all of their notes and materials aside. The test booklets were distributed and the test was taken by the participants. The total time for the exercise was less than $1 \mathrm{~h}$.

\section{RESULTS}

The correlation between the interview accuracy test score and sum of the training scores was significant $(r=.54, p<.01)$.

The mean for listening accuracy in this experiment was 21.69. In an earlier experiment (Schuh, 1978b) 
with the same test and participants drawn from the same population, the mean was 18.65 . However, in the earlier study, the students were tested without the benefit of the alerting and clarifying procedures used in this experiment. The increase in listening accuracy of 3.04 items was a $16 \%$ increase over that obtained in the earlier study and was significant $(t=5.85, \mathrm{p}<.001)$. The Kuder-Richardson Formula 21 reliability estimate of the listening accuracy test was .66 based on other research that had a broader range of talent and larger sample size (Schuh, 1978a).

\section{DISCUSSION}

The effect of alerting participants that they would be tested on their listening and showing two sample interviews to aid the participants in clarifying what the demands of the criterion task would be yielded a statistically significant $16 \%$ increase in listening effectiveness over the base rate established in an earlier study (Schuh, 1978b). One of the implications to practice might be that prior to performing interviewing duties, interviewers and managers should be carefully briefed on the nature of the demands that will be made on their memories upon completion of the listening experience. As in the earlier study, participants were required to take the test from memory without the aid of notes. In practical employment settings, those performing interviewing duties use their notes for rehearsal. Thus, the $16 \%$ increase should be seen as a lower bound on the payoff to be expected from the alerting and clarifying procedures.

The boost in listening accuracy does not destroy the correlation between the listening accuracy test score and the training scores. The correlation of .54 is not significantly different from the .43 obtained in the earlier study. The use of training scores to predict who will be the better listeners remains a viable recommendation.

\section{REFERENCE NOTE}

1. Cronbach, L. J. Personal communication, August 24, 1978.

\section{REFERENCES}

CRONBACH, L. J. Essentials of psychological testing. New York: Harper \& Row, 1970.

Schuн, A. J. Effects of an early interruption and note taking on listening accuracy and decision making in the interview. Bulletin of the Psychonomic Society, 1978, 12, 242-244. (a)

Scrum, A. J. Predicting listening accuracy in the interview with training scores. Bulletin of the Psychonomic Society, 1978, 11, 281-282. (b)

(Received for publication January $31,1979$. ) 